\title{
Transcriptomic Profiling of 3D Glioblastoma Tumoroids for the Identification of Mechanisms Involved in Anticancer Drug Resistance
}

\author{
NIPHA CHAICHAROENAUDOMRUNG, PHONGSAKORN KUNHORM, WILASINEE PROMJANTUEK, \\ NARAWADEE RUJANAPUN, NUDJANAD HEEBKAEW, NATCHADAPORN SORAKSA and PARINYA NOISA \\ Laboratory of Cell-Based Assays and Innovations, School of Biotechnology, \\ Institute of Agricultural Technology, Suranaree University of Technology, Nakhon Ratchasima, Thailand
}

\begin{abstract}
Background/Aim: Among various types of brain tumors, glioblastoma is the most malignant and highly aggressive brain tumor that possesses a high resistance against anticancer drugs. To understand the underlined mechanisms of tumor drug resistance, a new and more effective research approach is required. The three dimensional $(3 D)$ in vitro cell culture models could be a potential approach to study cancer features and biology, as well as screen for anticancer agents due to the close mimicry of the $3 D$ tumor microenvironments. Materials and Methods: With our developed $3 D$ alginate scaffolds, Ilumina RNA-sequencing was used to transcriptomically analyze and compare the gene expression profiles between glioblastoma cells in traditional 2-dimensional (2D) monolayer and in 3D Ca-alginate scaffolds at day 14. To verify the reliability and accuracy of Illumina RNA-Sequencing data, ATP-binding cassette transporter genes were chosen for quantitative real-time polymerase chain reaction) verification. Results: The results showed that 7,411 and 3,915 genes of the 3D glioblastoma were up-regulated and down-regulated, respectively, compared with the 2D-cultured glioblastoma. Furthermore, the Kyoto Encyclopaedia of Genes and Genomes pathway analysis revealed that genes related to the cell cycle and DNA replication were enriched in the group of down-regulated gene. On the other hand, the genes involved in mitogen-activated
\end{abstract}

This article is freely accessible online.

Correspondence to: Parinya Noisa, Laboratory of Cell-Based Assays and Innovations, School of Biotechnology, Institute of Agricultural Technology, Suranaree University of Technology, Nakhon Ratchasima, 30000, Thailand. Tel: +66 616266390, Fax: +66 44224154, e-mail: p.noisa@ sut.ac.th

Key Words: Transcriptomics, 3D tumoroids, anticancer drug screening, glioblastoma. protein kinase signaling, autophagy, drug metabolism through cytochrome P450, and ATP-binding cassette transporter were found in the up-regulated gene collection. Conclusion: $3 D$ glioblastoma tumoroids might potentially serve as a powerful platform for exploring glioblastoma biology. They can also be valuable in anti-glioblastoma drug screening, as well as the identification of novel molecular targets in clinical treatment of human glioblastoma.

Glioblastoma is one of the most common yet aggressive malignant primary human brain tumors, originating from astrocytes or their precursors (1). Numerous efforts have been invested in developing the clinical treatment of glioblastoma including radiation therapy, neurosurgery and chemotherapy. However, even with good, consistent treatment, patients tended to survive for only 14 months, with the recurrence of glioblastoma at 5-7 months post-treatment (2). A unique characteristic of glioblastoma is their infiltrative ability to diffusively invade normal brain tissue $(3,4)$, which is possibly the cause of high recurrence and anticancer drug resistance (5). In order to primarily understand the biology of this glioblastoma type and reveal the underlying mechanism of anticancer drug resistance, an effective in vitro tumor model is needed. However, in vitro studies based on 2D culture cannot correctly imitate the in vivo architecture and microenvironments within which cancer cells reside. Therefore, cells under 2D culture are different from those growing in vivo in terms of proliferation, morphology, cellcell and cell-matrix interconnections, signal transduction, and transcriptomic profile $(6,7)$. In order to recapitulate such cell microenvironments in vivo, three-dimensional (3D) culture has been alternatively used as in vitro tumor models, which can simulate in vivo cell behaviors, and provide more comparable and reliable results (8). Several 3D in vitro glioblastoma models have been established using extracellular matrix-based scaffolds and elucidated the dramatic differences in terms of cell proliferation, morphology, and 

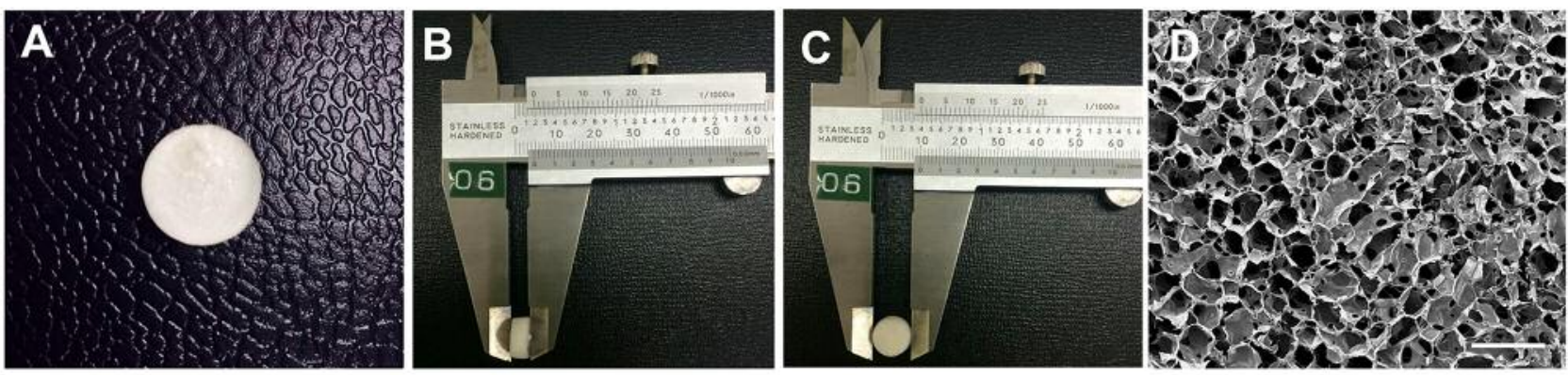

Figure 1. A: Morphology of Ca-alginate scaffolds. Disk-shaped Ca-alginate scaffold, which $5 \mathrm{~mm}$ in height (B) and $10 \mathrm{~mm}$ in diameter (C). D: Scanning electron microscopy images of the Ca-alginate scaffold. Scale bar: $500 \mu \mathrm{m}$.

drug resistance between $2 \mathrm{D}$ and $3 \mathrm{D}$ glioblastoma cells in culture (9-11). Our previous study reported the up-regulation of genes associated with stemness and differentiation, and vascular endothelial growth factor (VEGF) angiogenesis factor in 3D glioblastoma, which might play important roles in the enhancement of drug resistance (11). Recently, several investigators have examined the effects of glioblastoma multiforme tumor cells culture condition on gene expression profiles. They found that in 3D glioblastoma multiforme PLA porous scaffolds compared to the $2 \mathrm{D}$ condition, genes in peroxisome proliferator-activated receptors and phosphatidylinositol 3'-kinase(PI3K)-AKT signaling pathways were up-regulated, while those in metabolism, or related to the extracellular matrix and transforming growth factor-beta pathways were down-regulated (12). Tejero, et al. found that the 3D glioblastoma organoids promoted the appearance of a quiescent cell population that represented the self-renewal ability high therapy resistance, and mesenchymal gene signatures (13). Furthermore, Jia, et al. found that the expression of genes associated with stemness, cell cycle, apoptosis, epithelia-mesenchymal transition, migration, invasion, and glioma malignancy, were upregulated in 3D glioma cell culture (14). Despite the number of 3D glioblastoma studies, the transcriptomic profile and molecular pathway need to be further explored in order to understand the global picture of the underlying drug resistance mechanism. In this study, the transcriptomic profiles of glioblastoma cells under 2D and 3D conditions were elucidated and analyzed using next-generation sequencing technology (Illumina HiSeq systems) to emphatically reveal pathways related to anticancer drug resistance in $3 \mathrm{D}$ in vitro glioblastoma.

\section{Materials and Methods}

Chemicals and reagents. Sodium alginate, arginine-glycine-aspartate and calcium chloride were purchased from Sigma-Aldrich Chemical Co. (St. Louis, MO, USA). Calcein-AM, propidium iodide (PI), and 4, 6-diamidino-2-phenylindole were purchased from Life
Technologies Inc. (Carlsbad, CA, USA). The U-251 human glioblastoma cell line was obtained from the European Collection of Authenticated Cell Cultures (Salisbury, UK). Dulbecco's modified Eagle's medium (DMEM) and fetal bovine serum (FBS) were obtained from HyClone (HyClone, Logan, UT, USA), while nonessential amino acids, $0.5 \%$ trypsin-ethylenediaminetetra-acetic acid and L-glutamax were purchased from Gibco (GIBCO, Carlsbad, CA, USA).

Fabrication of porous scaffolds. Ca-alginate scaffolds for 3D cell culture were fabricated using freeze-drying technique as described in our previous study (11). Briefly, $2 \%$ sodium alginate was dissolved in sterile deionized (DI) water. The sodium alginate solution was injected into 48 -well culture plate at a volume of 400 $\mu \mathrm{l} /$ well. Sodium alginate solution was then frozen at $-20^{\circ} \mathrm{C}$ for 24 $\mathrm{h}$ prior to lyophilization to generate porous scaffolds. The scaffolds were cross-linked with $2 \%$ calcium chloride solution, washed several times with sterile DI water. The scaffolds were then sterilized with alcohol (75\%) for $24 \mathrm{~h}$, and stored at room temperature until use. Before use, the scaffolds were washed several times with sterile DI water, immersed in $100 \mathrm{mg} / \mathrm{l}$ arginine-glycineaspartate peptide solution, and incubated overnight at $37^{\circ} \mathrm{C}$ in a humidified incubator supplied with $5 \% \quad \mathrm{CO}_{2}$ and $95 \%$ air. Morphology of Ca-alginate scaffold was evaluated and is shown in Figure 1. The porous structure of the Ca-alginate scaffolds was examined using scanning electron microscopy, demonstrating 100$400 \mu \mathrm{m}$ pore size with the average $89 \%$ porosity.

Cell cultures. U-251 glioblastoma cell line was used as a model in this study. For 2D cell culture, 50,000 cells of U-251 in 200 complete DMEM (supplemented with $10 \% \mathrm{v} / \mathrm{v}$ FBS, $1 \% \mathrm{v} / \mathrm{v}$ penicillinstreptomycin, $1 \% \mathrm{v} / \mathrm{v}$ L-glutamine, and $1 \% \mathrm{v} / \mathrm{v}$ nonessential amino acids) was added to each well of the 24 -well cell culture plate. Cells were then incubated at $37^{\circ} \mathrm{C}$ with $5 \% \mathrm{CO}_{2}$. Complete medium was replenished every 2 days with fresh. Morphology of cells was observed under an inverted microscope (Nikon Eclipse TS2; Nikon Inc., Melville, NY, USA).

For 3D cell culture, Ca-alginate scaffolds were placed in 24-well cell culture plate with complete DMEM overnight prior to cell seeding. After 1 -h incubation at $37^{\circ} \mathrm{C}$ and $5 \% \mathrm{CO}_{2}$ in a humidified incubator, 50,000 cells in $50 \mu \mathrm{l}$ of complete DMEM were seeded directly onto each scaffold. Then $1 \mathrm{ml}$ of complete medium was added to each well before further cultivation under the same conditions. Complete DMEM was renewed once every 2 days. 
Table I. The primer sequences used for real-time quantitative real-time polymerase chain reaction.

\begin{tabular}{lll}
\hline Gene & Forward primers & Reverse primers \\
\hline GAPDH & 5'-CTCTGCTCCTCCTGTTCGAC-3' & 5'- TTAAAAGCAGCCCTGGTGAC-3' \\
$A B C A 1$ & 5'-GCACTGAGGAAGATGCTGAAA-3' & 5'-AGTTCCTGGAAGGTCTTGTTCAC-3' \\
$A B C A 2$ & 5'-CATCCCCCTGGTGCTGTTCTT-3' & 5'-GCTTGGGCCGTGCTATTGG-3' \\
$A B C A 3$ & 5'-GCCCTCTTTACACTCAGTTTTCA-3' & 5'-GACGAGCAGTTGTCGTACCTAAT-3' \\
$A B C A 5$ & 5'-TTATGGCAGTCATTGCGACAG-3' \\
$A B C A 6$ & 5'-CCGTCAAGGGGCTCAGGAA -3' & 5'-AAAGAGGTGTCAGCATTAAAGCA-3' \\
$A B C A 8$ & 5'- AGTGCGCGGGCTCTTCTTTGT-3' & 5'-GATGGCCACACGGTCACAC -3' \\
$A B C A 9$ & 5'-GTTTCCTTCGCTTTTGGCTGATA-3' \\
$A B C A 10$ & 5'-GCCATGATGAAAGAGCACAGAG-3' \\
$A B C A 12$ & 5'-TCTCGCCGAAGTATATGGGATGTT-3' & 5'-AGGATCCCCCAAAAGACAATAAGG-3' \\
\hline
\end{tabular}

GAPDH: Glyceraldehyde 3-phosphate dehydrogenase; $A B C$ : ATP-binding cassette subfamily A.

Live/dead cell calcein-AM and PI fluorescent double staining was performed to assess cell viability inside the Ca-alginate scaffolds.

RNA extraction. Total RNA from U-251 cells after 14 days under both 2D and 3D cell culture was extracted with NucleoSpin RNA Kit (Macherey-Nagel, Dueren, Germany) according to the manufacturer's instructions (three replications each). Additionally, for cells under 3D conditions, $50 \mathrm{mM}$ ethylenediaminetetra-acetic acid solution was added onto Ca-alginate scaffolds for cell isolation. Cells were then washed with phosphate-buffered saline and collected by centrifugation at $60 \times g$ for $3 \mathrm{~min}$. The total RNA from each sample was quantified and qualified by NanoDrop ${ }^{\circledR}$ (Thermo Fisher Scientific Inc, Waltham, MA, USA) at $\mathrm{OD}_{260} \mathrm{~nm} / \mathrm{OD}_{280} \mathrm{~nm}$ and Agilent 2100 Bioanalyzer (Agilent Technologies, Palo Alto, CA, USA), respectively. The integrity of these RNA samples was checked by $1 \%$ agarose gel electrophoresis. One microgram of total RNA with RNA integrity number value above 7 was used for the subsequent library preparation.

RNA sequencing library construction. RNA-seq library preparation, sequencing and analysis were carried out by Vishuo Biomedical Ltd. (Thailand) Next-generation sequencing library preparations were constructed according to the manufacturer's protocol (NEB$\mathrm{Next}^{\circledR}{ }^{\circledR}$ Ulra $^{\mathrm{TM}}$ RNA Library Prep Kit for Illumina ${ }^{\circledR}$; Illumina, New England Biolabs Inc., Ipswich, MA, USA). Poly(A) mRNA isolation was performed using NEBNext Poly(A) mRNA Magnetic Isolation Module (NEB) or Ribo-Zero ${ }^{\mathrm{TM}}$ rRNA removal Kit (Illumina). mRNA fragmentation and priming was performed using NEBNext First-Strand Synthesis Reaction Buffer and NEBNext Random Primers. First-Strand cDNA was synthesized using ProtoScript II Reverse Transcriptase and the second-strand cDNA was synthesized using Second Strand Synthesis Enzyme Mix. Purified doublestranded cDNA produced using AxyPrep Mag polymerase chain reaction Clean-up (Axygen Scientific Inc., Union, CA, USA) was then treated with End Prep Enzyme Mix to repair both ends and add a dA-tailing in one reaction, followed by a T-A ligation to add adaptors to both ends. Size selection of Adaptor-ligated DNA was then performed using AxyPrep Mag polymerase chain reaction (PCR) Clean-Up (Axygen), and fragments of $\sim 360$ bp (with the approximate insert size of $300 \mathrm{bp}$ ) were recovered. Each sample was then amplified by PCR for 11 cycles using P5 and P7 primers, with both primers carrying sequences which can anneal with flow cell to perform bridge PCR and P7 primer carrying a six-base index allowing for multiplexing. The PCR products were cleaned up using AxyPrep Mag PCR Clean-up (Axygen), validated using an Agilent 2100 Bioanalyzer (Agilent Technologies), and quantified by Qubit 2.0 Fluorometer (Invitrogen, Carlsbad, CA, USA). Libraries with different indices were multiplexed and loaded on an Illumina HiSeq instrument according to manufacturer's instructions (Illumina). Sequencing was carried out using a $2 \times 150 \mathrm{bp}$ paired-end (PE) configuration; image analysis and base calling were conducted by the HiSeq Control Software (HCS) + OLB + GAPipeline-1.6 (Illumina) on a HiSeq instrument. The sequences were processed by the Genewiz Biotechnology Company (Jiangsu, Suzhou, PR China), and the basic bioinformatics data were analyzed by $R \& D$ genomics services at Vishuo Biomedical Pte. Ltd., Singapore.

Quantification of gene expression and differential expression analysis. To quality control, the raw data (raw reads) of fastq format were firstly processed by Trimmomatic (v0.30). In this step, the clean data (clean reads) were obtained by removing low-quality reads and those containing adapter. At the same time, the percentage of bases with quality scores higher than 20 or 30 (Q20, Q30), and GC content of the clean data were calculated. All downstream analyses were based on the clean data of high quality. The reference genome sequences and gene model annotation files of relative species were then downloaded from genome website (UCSC, NCBI, ENSEMBL). Hisat2 (v2.0.1) was then used to index reference genome sequence. The clean data were aligned to reference genome via Hisat2 (v2.0.1) software. HTSeq (v0.6.1) estimated gene and isoform expression levels from the pairend clean data (15). Differential expression analysis used the DESeq Bioconductor package, a model based on the negative binomial distribution. After adjusting by Benjamini and Hochberg's approach for controlling the false-discovery rate, $p$-values for genes of were set at less than 0.05 to detect differentially expressed ones $(15,16)$.

Bioinformatics evaluation. The genes differentially expressed of between 2D and 3D cultures of U-251 cells were analyzed by evaluating the Gene Ontologies (GO) and using the Kyoto Encyclopedia of Genes and Genomes (KEGG) software for pathway evaluation. GO-TermFinder was used to identify GO terms that annotated enriched genes with a significant $p<0.05$. In-house scripts were used to enrich genes with significant differential expression in KEGG pathways. 


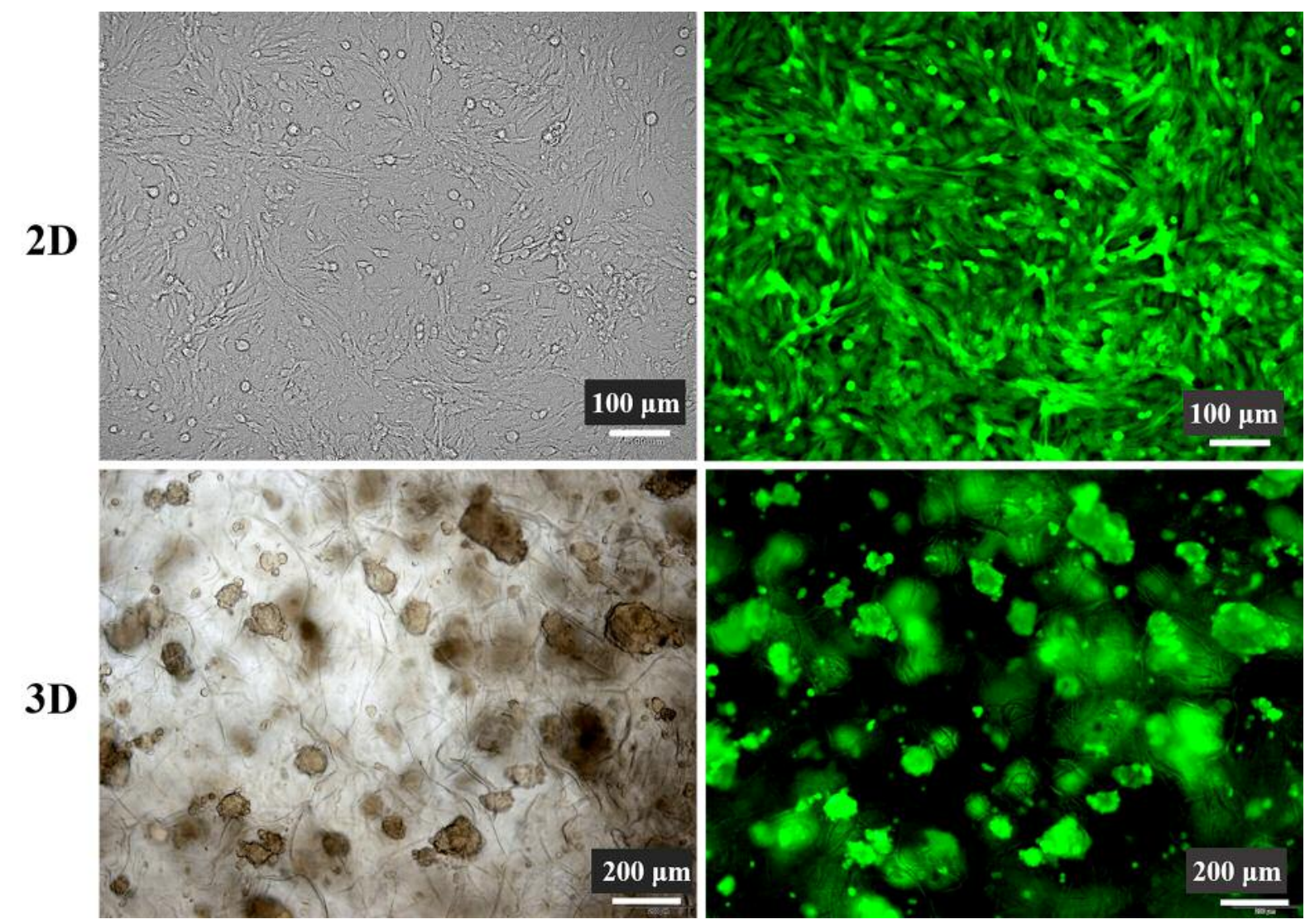

Figure 2. Morphology of glioblastoma cells cultured under $2 D$ and $3 D$ conditions for 14 days.

Quantitative real-time ( $q R T$ ) PCR validation. To further validate the accuracy of DESeq2 results, qRT-PCR analyses were performed. RNA samples from 2D and 3D cell cultures at day 14 were collected and reverse transcribed using ReverTra Ace ${ }^{\circledR}$ qPCR RT Master Mix with gDNA Remover (Toyobo, Osaka, Japan). The cDNA transcription was used as template for quantitative real time PCR mixed with qPCR BioSyGreen Mix Low-Rox (PCR BIOSYSTEMS, London, UK) by thermocycling using QuantStudio 5 Real-Time PCR System (Thermo Fisher Scientific), using the following program: $95^{\circ} \mathrm{C}$ for $3 \mathrm{~min}$ followed by 40 cycles of $95^{\circ} \mathrm{C}$ for $30 \mathrm{~s}$ and $60^{\circ} \mathrm{C}$ for $30 \mathrm{~s}$ and $72^{\circ} \mathrm{C}$ for $45 \mathrm{~s}$. A melting curve analysis of the PCR products was performed by heating at $60^{\circ} \mathrm{C}$ for $60 \mathrm{~s}, 95^{\circ} \mathrm{C}$ for $15 \mathrm{~s}$. Glyceraldehyde-3-phosphate dehydrogenase $(G A P D H)$ was selected as the reference gene. The expression levels of $A$ TP binding cassette subfamily A member ( $A B C A 1, A B C A 2$, $A B C A 3, A B C A 5, A B C A 6, A B C A 8, A B C A 9, A B C A 10$, and $A B C A 12)$ were examined. The primers designed for the genes of interest are shown in Table I. The relative expression of these genes for 3D cell cultures compared those in with $2 \mathrm{D}$ culture was determined by the $2^{-} \Delta \Delta \mathrm{Ct}$ method, and each target gene was normalized against the $G A P D H$ reference gene.

Statistical analysis. The results are expressed as mean values \pm standard deviation. Comparison between different groups was performed using Student's $t$-test (SPSS version 16.0; SPSS Inc., Hong Kong, China). Differences were considered significant $p \leq 0.05$.

\section{Results}

U-251 glioblastoma cell culture. The morphology of the U251 cells in the 2D and 3D culture condition at day 14 was examined using fluorescence microscopy. Cells cultured under conventional 2D conditions tended to grow as flat monolayer sheets, while cells cultured under 3D conditions managed to expand intercellular interactions to form cell spheroids similarly to in vivo tumor. After 14 days of $3 \mathrm{D}$ cell culture, spheroids with the diameter of up to $50 \mu \mathrm{m}$ were found in the culture system (Figure 2).

Transcriptome sequencing and mapping to the reference genome. During sequencing, quality concerns may arise. A small number of target sequences might be read into adapter sequences, and bases toward the 3'-end might have low quality due to the lengthy sequencing cycles. In order to eliminate the negative effect of these technical issues, lowquality reads and contaminations were filtered out before data analysis. In addition, adapter sequences were removed. A total of $283,439,522$ raw reads were primarily generated; after removing low-quality reads and those containing adapter and poly-N, 281,713,096 clean reads remained (Table II). The 
Table II. Data quality, filtration and alignment summary for transcriptome of U-251 cells under $2 D$ and $3 D$ culture conditions.

\begin{tabular}{lcccccccc}
\hline $\begin{array}{l}\text { Culture } \\
\text { condition }\end{array}$ & Sample & Raw reads & Clean reads & Clean bases & Q20 (\%) & Q30 (\%) & GC (\%) & Total mapped \\
\hline 2D & 1 & 46709780 & 46436476 & 6877710088 & 96.84 & 91.55 & 50.56 & $44158319(95.094 \%)$ \\
& 2 & 48927824 & 48635394 & 7216851609 & 96.76 & 91.38 & 50.63 & $46244539(95.0841 \%)$ \\
& 3 & 42611526 & 42392708 & 6285675863 & 97.23 & 92.52 & 51.16 & $40369758(95.2281 \%)$ \\
3D & 1 & 54972942 & 54654512 & 8111036223 & 97.13 & 92.33 & 50.46 & $51449161(94.1352 \%)$ \\
& 2 & 47101130 & 46831888 & 6945874735 & 97.13 & 92.34 & 50.69 & $43872697(93.6812 \%)$ \\
& 3 & 43116320 & 42762118 & 6331575923 & 96.81 & 91.79 & 50.25 & $39743105(92.94 \%)$ \\
\end{tabular}

Q20, Q30: Percentage of bases with quality scores higher than 20 or 30; GC: GC content of the clean data.

remaining clean data were used to map to the reference genome. From cells under 2D conditions, samples 2D-1, 2D2, and 2D-3 had $95.094 \%, 95.0841 \%$, and $95.2281 \%$ of reads mapped to the reference genome, respectively. From cells under 3D conditions, the percent of reads mapped to the reference genome of samples 3D-1, 3D-2, and 3D-3 were $94.1352 \%, 93.6812 \%$, and $92.94 \%$, respectively.

Differential gene expression between $2 D$ and $3 D$ culture conditions. The level of gene expression was measured by read density; the higher the read density, the higher the level of gene expression. The expected number of fragments per kilobase of target transcript length per million reads mapped (FPKM) is the most common method used to evaluate the level of gene expression (17). Collaboratively, principal component analysis (PCA) was used to reduce data complexity and analyze the sample relationship and the scale of the difference between the transcriptomes of $2 \mathrm{D}$ and $3 \mathrm{D}$ condition. The results of PCA revealed the significant difference between these two conditions (Figure 3A). Moreover, the DESeq2 differential expression analysis was further analyzed to specifically determine genes with significant differential gene expression profile between the groups. The significant differential gene expression was defined based on a fold change greater than 2 or less than -2 and false-discovery rate less than 0.05 to achieve both statistical and biological significance (Figure 3B). Based on these standards, the differential gene expression of U-251 glioblastoma comparing between cells under $2 \mathrm{D}$ and $3 \mathrm{D}$ conditions was recorded. As shown in Figure 3C, 7,411 genes were found to be up-regulated and 3,915 genes were down-regulated during 14 days of culture. Detailed differentially expressed genes between 2D and 3D conditions are provided in Supplementary Table I (https://drive. google.com/file/d/1NJkEtX_PejBjC5ptY8LAFo3HZdX7QW se/view?usp=sharing). The heatmap and hierarchical clustering of all six samples, highlighting relative gene expression of the three replications of the 2D and 3D cell cultures is shown in Figure 4. According to the gene clustering heat map, cells under 3D culture conditions exhibited the highest level of variation in gene expression compared to those under 2D culture conditions.

Differential gene GO enrichment analysis. To explore the functions of the differentially expressed genes, GO analysis was further performed as the classification system for gene function, including molecular function, cellular components, and biological processes. The differentially expressed genes mainly enriched under 3D culture conditions in the category of molecular function were the genes related to binding, catalytic activity, transporter activity. In the cellular components category, cells part, organelle, organelle part, membrane part, membrane, macromolecular complex, extracellular region, extracellular region part, and cell junction showed significant proportions of differential gene expression. Among genes categorized in the biological process category, genes related to cellular process, biological regulation, singleorganism process, metabolic process, developmental process, response to stimulus, localization, cellular component organization, multicellular organismal process, immune system process and multi-organism process showed the most significant differential expression (Figure 5).

KEGG pathway analysis of $U-251$ cells cultured under $2 D$ and $3 D$ conditions. Physiological activities are the result of 'cooperation' between genes with various functions. Pathway functional enrichment facilitates the determination of differentially expressed genes involved in the most important biochemical metabolic pathways and signal transduction pathways. KEGG is the primary public pathway database (18) used for this type of analysis. Pathway enrichment analysis performed in this section was based on KEGG pathway units with a hypergeometric test to highlight the pathways of the differentially expressed genes significantly enriched against the transcriptome background. The differential gene expression was mainly enriched in mitophagy, autophagy, extracellular matrix-receptor interaction, cell cycle, fatty acid metabolism, RNA degradation, pyrimidine metabolism, DNA 
A

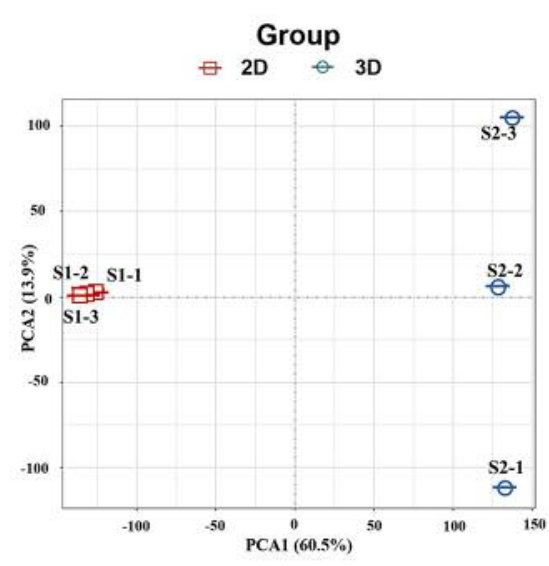

B

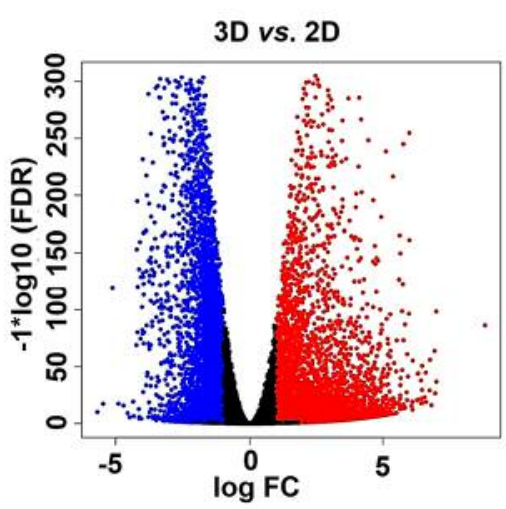

C

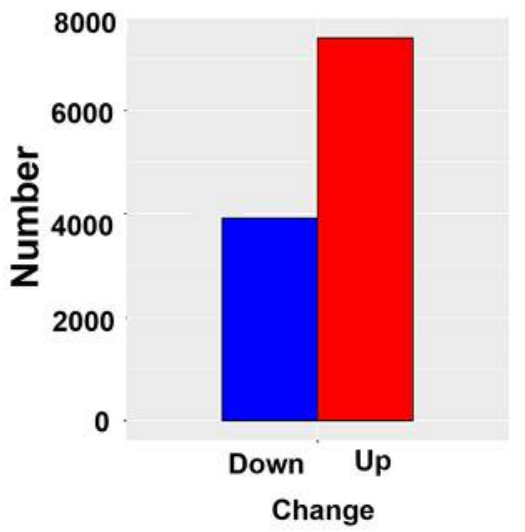

Figure 3. A. Principal component analysis (PCA) chart demonstrating the correlation between samples. B: Volcano plot of differential gene expression. Red dots represent genes that were significantly up-regulated and blue dots represent those that were significantly down-regulated in $3 D$ compared with $2 D$ culture. Abscissa represents multiple genes expressed in different samples. Ordinate represents the magnitude of gene expression change. C: Bar graph of the frequency of genes significantly up- or down-regulated between $2 D$ and $3 D$ conditions. FC: Fold change; FDR: false-discovery rate.

replication, pathways in cancer, viral carcinogenesis, steroid biosynthesis, and mitogen-activated protein kinase (MAPK) signaling pathway. Here, some important pathways were revealed the major differences in glioblastoma cells cultured under $2 \mathrm{D}$ and $3 \mathrm{D}$ conditions, as well as pathways that cause the anticancer drug resistance of glioblastoma. The results based on KEGG pathway analysis showed the downregulated genes were mainly enriched in pathways related to the cell cycle and DNA replication, while the up-regulated genes were mainly enriched in MAPK signaling, autophagy, drug metabolism-cytochrome $\mathrm{P} 450$, and ABC transporter pathway. Heatmaps were generated based on the differentially expressed genes of each particular pathway defined by FPKM value (Figure 6).

$R T-q P C R$ verification. To further validate the results of Illumina RNA-Sequencing data, qRT-PCR was performed to investigate the mRNA expression of $A B C A 1, A B C A 2, A B C A 3$, $A B C A 5, A B C A 6, A B C A 8, A B C A 9, A B C A 10$ and $A B C A 12$. The validation qRT-PCR results are shown in Figure 7. The mRNA expression of these genes in cells under 3D culture was significantly higher than that of 2D cell culture, by 3-fold or higher. These results indicate that all genes showed consistent expression patterns with the Illumina RNA-Sequencing data, confirming that our experimental results were valid.

\section{Discussion}

2D cell culture has been used for in vitro models in drug screening for primary identification and verification of bioactive compounds that were subsequently translated into clinical cancer treatment (19). However, there was poor correlation in terms of the effectiveness of emerging anticancer agents tested in 2D cell culture in that of the actual treatment in patients, which emphasizes the need for the development of novel, effective and translatable in vitro models (20). Culture conditions are known to crucially affect the regulation of cell fate and responsiveness of cells to external stimuli. 2D culture conditions are widely favored due to their easy and fast testing capability but cells grown in such conditions may lose their natural phenotypic and functional characteristics (21). The limitations of 2D cell culture might be overcome by culturing cells under more physiological 3D conditions. Thus, 3D in vitro tumor models would be powerful and effective tool, in cancer research and low-cost anticancer drug screening $(10,11)$. Closely imitating the complex in vivo tumor microenvironment helps researchers to reveal and understand the underlying molecular mechanism for tumorigenesis, development, proliferation, migration, invasion, angiogenesis, and resistance to anticancer drugs.

In the present study, we utilized a 3D Ca-alginate scaffold as a model to create glioblastoma micro tumor spheroids and analyze their global gene expression profiles when cultured under 2D and 3D culture condition by Illumina RNAsequencing. Furthermore, we identified the putative pathways enriched with differentially expressed genes, which potentially play a crucial role in the enhancement of anticancer drug resistance in glioblastoma.

Several RNA-sequencing studies demonstrated significant, tumor-relevant molecular changes induced by $3 \mathrm{D}$ cell culture $(12,22,23)$. Glioblastoma spheroids in 3D culture mimicked in vivo tissues, organs and even patient tumors, providing 


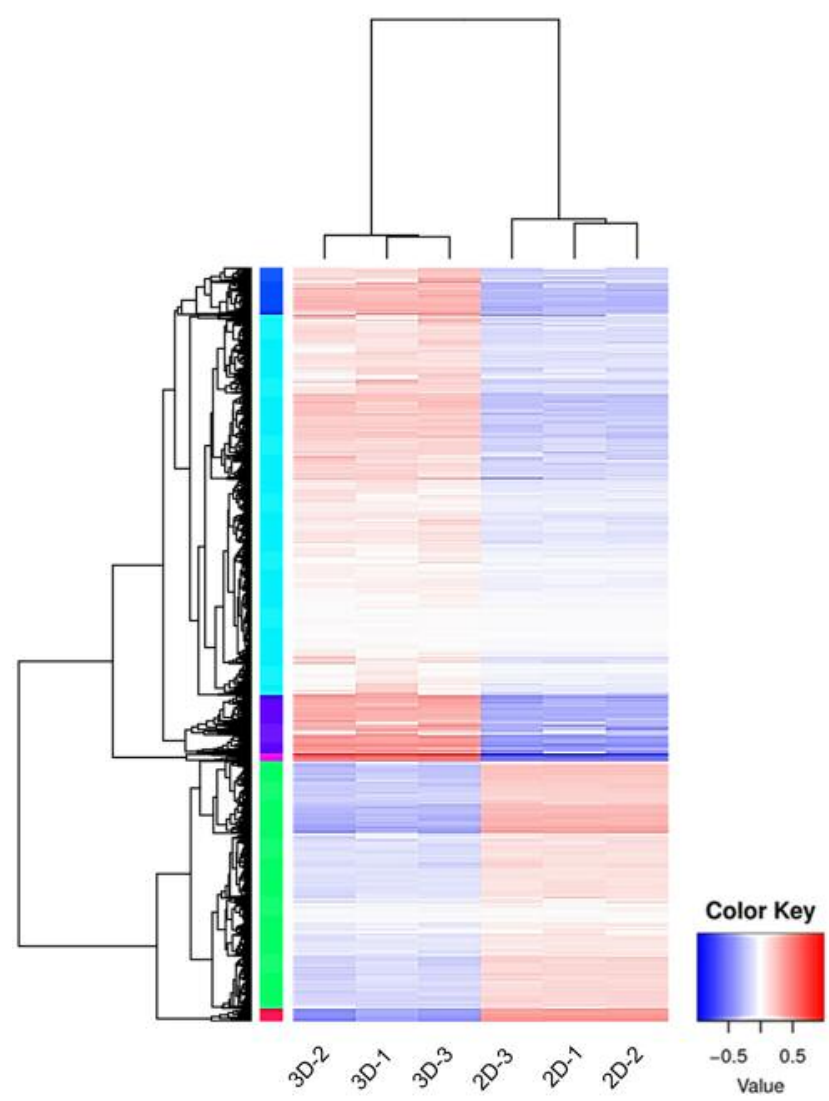

Figure 4. Heatmap of gene expression in glioblastoma cells under $2 D$ and $3 D$ culture conditions for 14 days. 2D-1 to -3: Replicates 1-3 under $2 D$ culture conditions; $3 D-1$ to -3 : Replicates 1-3 under $3 D$ culture conditions.

similar cellular properties including hypoxic gradients, cellular heterogeneity with both slow-dividing cells and proliferative tumor bulk $(24,25)$ and higher drug resistance (10). Our transcriptomic study provides other evidence of the global molecular alterations due to different microenvironments under 2D and 3D cell culture conditions, especially for the expression of genes related to the cell cycle, DNA replication, MAPK signaling, autophagy, drug metabolism-cytochrome $\mathrm{P} 450$, and $\mathrm{ABC}$ transporter pathway.

Among all crucial cellular properties found to be different in our 3D model of glioblastoma, cell proliferation governed by the cell cycle pathway seemed to exhibit the most dramatic alteration. In our experiments, there were 56 differentially expressed genes downregulated in this pathway comparing between 2D and 3D condition (Figure 6A). The cell cycle pathway is the series of events that control cell division. Regulation of the cell cycle is related to the survival of cells, including the detection and repair of genetic damage, as well as the prevention of uncontrolled cell division. Since 3D glioblastoma spheroids are known to feature the hypoxic gradients and cellular heterogeneity which exist in tumors in vivo, such hypoxia many affect the cell cycle. Richards et al. demonstrated that hypoxia has the potential to induce cell-cycle arrest in glioblastoma cells (26). 3D glioblastoma cells residing within nutrient- and oxygen-deprived regions are mostly quiescent. Transcriptional profiling data revealed that quiescent stem cells were characterized by the down-regulation of genes associated with cell-cycle progression [i.e. cyclin A2 (CCNA2), $C C N B 1$, and CCNE2] (27). Consistent with this, our study showed the expression of genes related to the cell cycle, such as CCNA1, CCND3, CCNB1, CCNB2, CDC14, CDC20 and polo like kinase 1(PLKI), were down-regulated under $3 \mathrm{D}$ culture conditions. DNA replication pathway, the series of biological processes by which DNA replication occurs during the S-phase of the cell cycle, also exhibited major differential gene expression. A total of 28 genes in the DNA replication pathway were found to be down-regulated under 3D conditions compared to 2D conditions (Figure 6B), which was possibly the consequences of cell-cycle arrest.

Despite the suppression of proliferation, reflected in the down-regulation of cell cycle and DNA replication pathways, the MAPK signaling pathway, which regulates cellular response to the extracellular signals, was affected in the opposite manner, in which 49 genes were found to be upregulated under 3D conditions (Figure $6 \mathrm{C}$ ). MAPK signaling pathway, often known as the RAS-RAF-MEK-ERK signal cascade, functions to transmit upstream extracellular signals to its downstream effectors. This pathway regulates a broad range of physiological processes such as cell growth, proliferation, differentiation, migration development, inflammatory responses and apoptosis (28) for cells in general, and the progression, invasion, survival and drug resistance in the context of cancer cells. Xu et al. demonstrated that MAPK8 promoted resistance to anticancer drug, accelerated cell proliferation and inhibited the apoptosis of glioblastoma cells via activating the MAPK signaling pathway (29). Other studies have reported that in tumor tissue samples derived from patient, extracellular signal-regulated protein kinase (ERK) was phosphorylated, indicating that this survival pathway was active in glioma cells (30). In addition, the MAPK/c-Jun $N$-terminal kinase (JNK) signaling transduction pathway was also reported to induce defensive mechanisms protecting against various stress situations and was been repeatedly linked to the molecular events involved in autophagy regulation (31). Lin et al. reported that temozolomide-induced autophagy was mediated by JNK activation in U87 cell lines, and the JNK inhibitor SP600125 inhibited cell autophagy, further increasing the percentage of cells undergoing apoptosis (32).

The involvement of MAPK signaling pathway in autophagy regulation conceivably may have contributed to up-regulation of 19 autophagy-related genes in our study (Figure 6D). Autophagy is a lysosomal-based degradative pathway that 


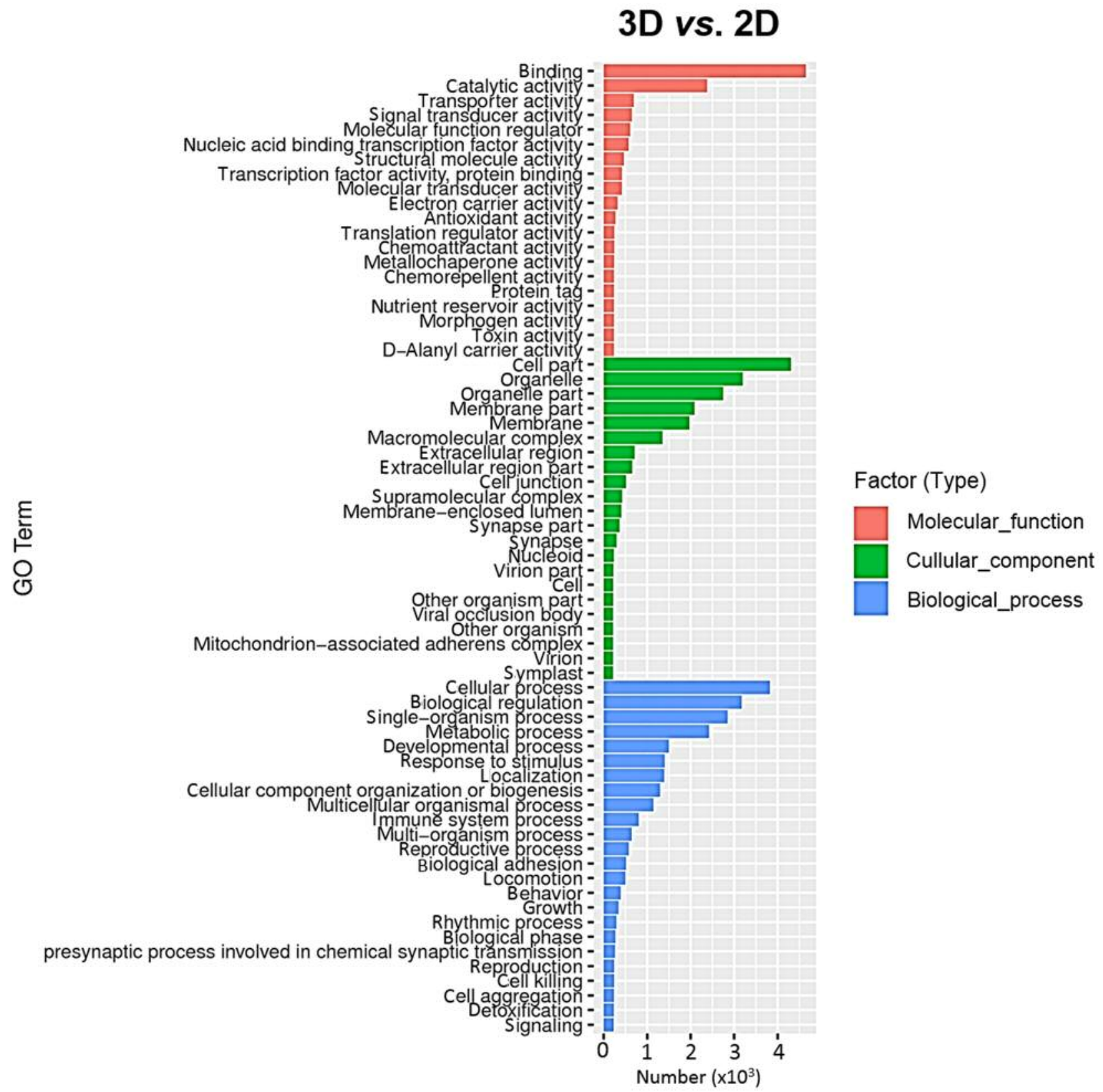

Figure 5. Gene Ontologies (GO) enrichment histogram. Color code is to distinguish the categories of biological processes, cellular components and molecular functions between $2 D$ and $3 D$ conditions.

processes self-cannibalization, allowing the degradation of intracellular components, including soluble proteins, aggregated proteins, organelles, macromolecular complexes, and foreign bodies to their relative biological building blocks during periods of starvation. Such self-eating and recycling provides cells with survival advantages under various stress situations (31). Autophagy can support growth of tumor at later stages, allowing tumor cells to survive with limited oxygen and nutrients, as well as under cytotoxic conditions caused by drug treatment (33). Bingel et al. found that autophagy-controlling transcription factors, such as transcription factor EB (TFEB) and forkhead box $\mathrm{O} 3$ (FOXO3) were up-regulated in tumors and 3D neuroblastoma cells and may underlie some mechanisms of chemotherapy resistance (33). In addition, 3D glioblastoma cells were able to undergo metabolic reprogramming to sustain their rapid growth and proliferation. 
A

Cell cycle

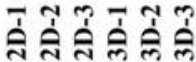

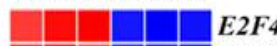

\begin{tabular}{ll|l}
\hline & & TFDPI
\end{tabular}

TFDP2

MYC

TGFB2

TGFB3

SKP2

\begin{tabular}{l|l|l|l|l}
\hline & & & & $R B 1$ \\
\hline & & & & \\
\hline
\end{tabular}

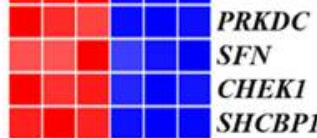

\begin{tabular}{|l|l|l|l|l|l}
\hline & & & & SHCBPI \\
\hline & & & & & BUB \\
\hline
\end{tabular}

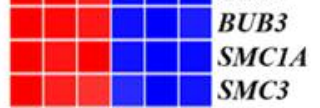

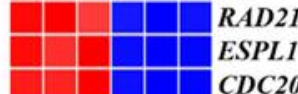

\begin{tabular}{c|c|c|c}
\hline & & & $C D C 20$ \\
\hline- & & & $C C N D 1$ \\
\hline & & & $C C N D 3$
\end{tabular}

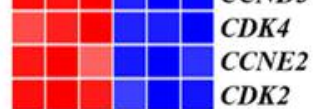

\begin{tabular}{c|c|c} 
& & \\
$C D K 2$ \\
- & & $C C N A 1$ \\
\hline & & $C C N H$
\end{tabular}

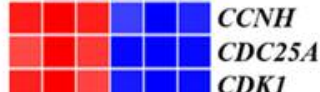

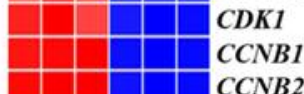

-

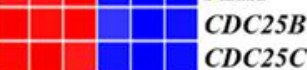

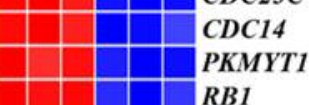

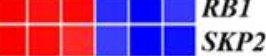

\begin{tabular}{l|l|l}
\hline & & $R B L 1$
\end{tabular}

\begin{tabular}{lll}
\hline & E2F4 \\
\hline & TFDP1
\end{tabular}

\begin{tabular}{l|l}
- & TFDP2
\end{tabular}

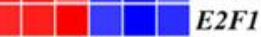

$-\quad-\quad E 2 F 2$

E2F

$+\quad-\quad$ CDC6

ORC1

ORC6

ORC3

ORC5

CDC45

MCM7

MCM4

MCM 2

PKMYT1

CDC7
B

DNA replication

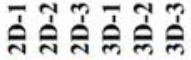

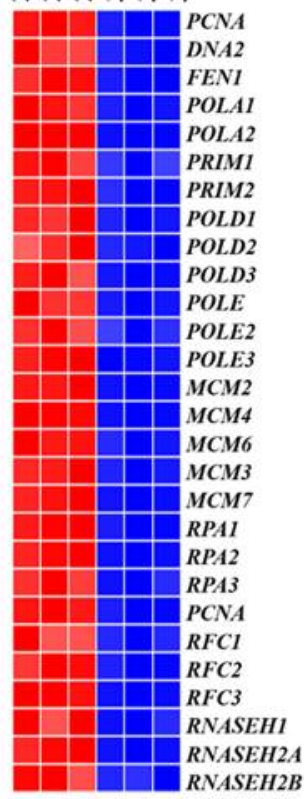

D

Autophagy pathway

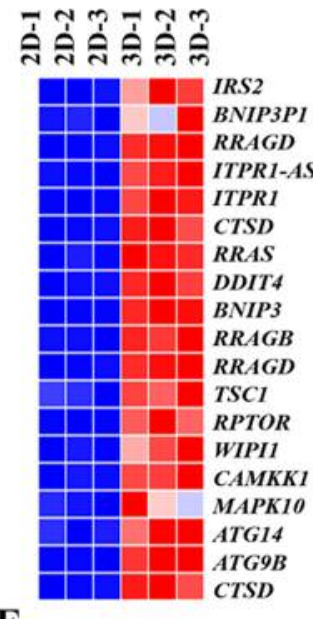

F

ABC transporter

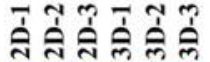

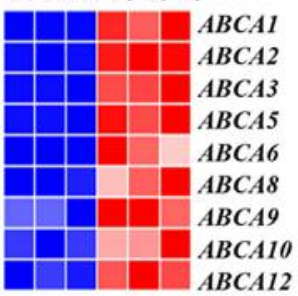

C MAPK signaling

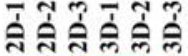
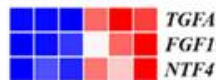

FLTSIG

$\square \quad \square \quad V E G F$

- 1 HGPT

EFNA

${ }_{C A F N A I}$
${ }_{C A C N B I}$

CACNB3

${ }^{C A C N A 2 D}$
${ }_{C A C N B A}$
${ }_{C C N B 2}$

CACNAID

CACNB2

$-\quad$ CACNAIA

RASGRP

RASGRP2
RISGRP

RRAS

NFI

- PRKCG

MAPT
PLA2GAD

- PTPRK

DUS

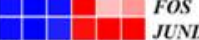

NGFR

INSRR

$-\int_{N F K B}$

RELE

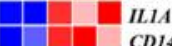

$-{ }_{\text {MAPSK12 }}^{\text {CD14 }}$

- MAPKSIP

FLNB

MAPKIO

- $\quad$ SYNGR

-1
DUSP

JUN

FOS

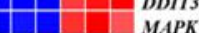

MAPK
$-{ }_{N R A I}$

- $\quad$ MAPKIIP

E Drug metabolismcytochrome $\mathbf{P 4 5 0}$

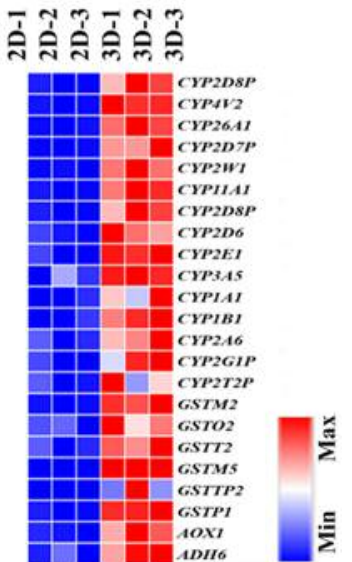

Figure 6. Differently expressed genes within pathways under $2 D(n=3)$ and $3 D(n=3)$ cell culture conditions after 14 days. A: Cell cycle. B: DNA replication. C: Mitogen-activated protein kinase (MAPK) signaling. D: Autophagy pathway. E: Drug metabolism-cytochrome P450. F: ATP-binding cassette $(A B C)$ transporters. 


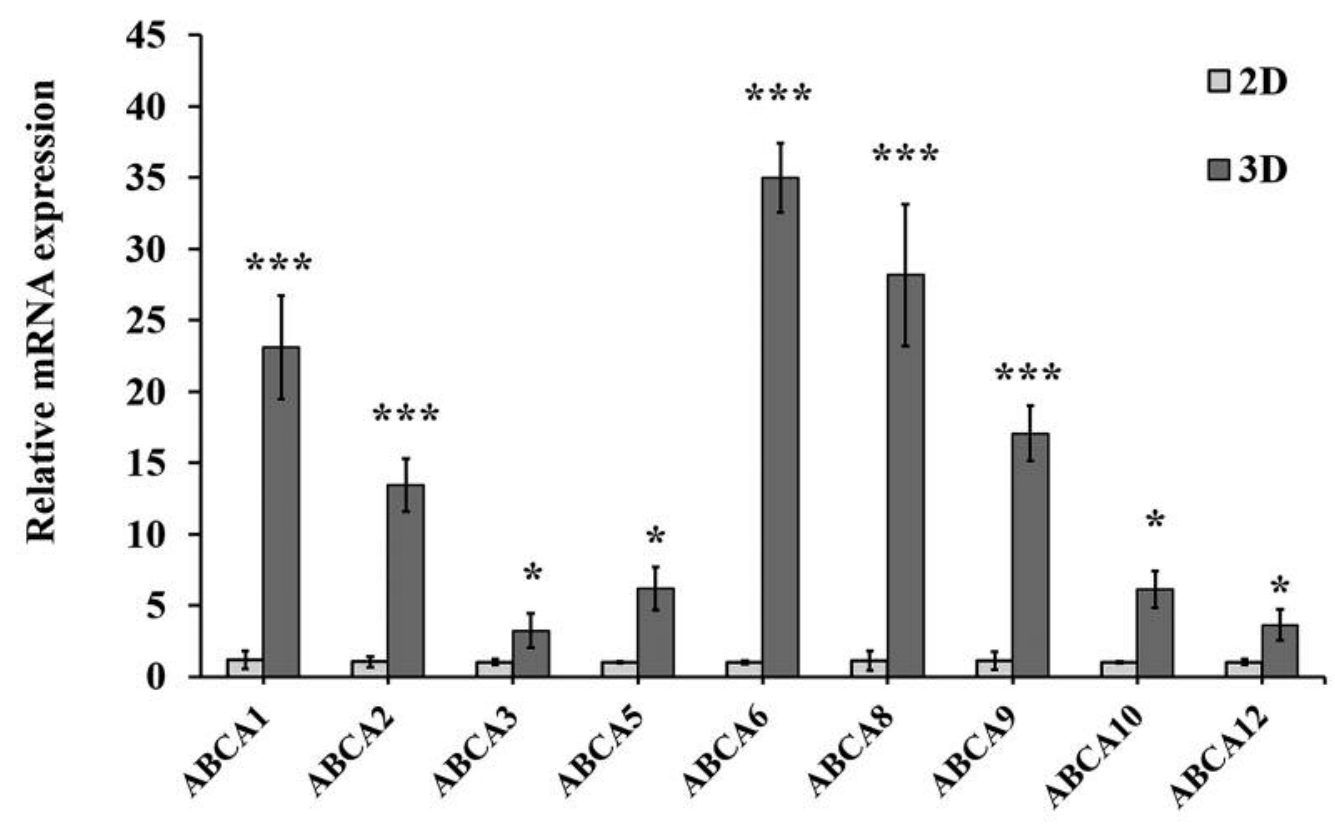

Figure 7. Expression of ATP-binding cassette $(A B C)$ transporter genes of glioblastoma cells after 14 days under $2 D$ and $3 D$ culture conditions. Significantly different by Student's t-test at: $* p<0.05, * * p<0.01$, and $* * * p<0.001$.

Hence, glioblastoma cells often have distinct nutrient requirements such as higher level of glucose, a phenomena associated with the Warburg effect which is characterized by a high glycolytic rate (34-36). The elevated rates of glucose uptake and metabolism to sustain their rapid growth combined with nutrient deprivation in glioblastoma spheroids may cause autophagy enhancement and the transition of cells to a quiescent state (37) and promote survival, and as such constitutes a vital mechanism of drug resistance (38). Wang et al. demonstrated that upon glucose starvation, while the majority of cancer cells perished due to chemotherapeutic cytotoxicity, subsets of cancer cells can up-regulate their autophagic activity, enter quiescence, and acquire survival advantage and ultimately chemoresistance (39).

Several mechanisms have been proposed for drug resistance of glioblastomas $(40,41)$. Intracellular drug inactivation may occur as a result of the increased concentrations of enzymes such as to glutathione $S$-transferase (GST), CYP450 and aldehyde dehydrogenases. These enzymes may have a role in reduced efficacy of chemotherapy against glioblastomas (42, 43). CYP450 plays a key role as phase I drug-metabolizing enzymes to catalyze the oxidative biotransformation of most drugs and other lipophilic xenobiotics (44). In this study, 23 genes in drug metabolism-CYP450 were found to be up-regulated in 3D glioblastoma (Figure 6E) which emphasizes the increase of malignancy of $3 \mathrm{D}$ glioblastoma comparing to those in $2 \mathrm{D}$. In the context of cancer, such family of enzymes are of particular interest since they exhibited important extrahepatic function and have been linked to various malignancies (45). Moreover, genotyping and epidemiological studies showed CYPlAl was correlated with increased risk for brain tumor (46). $C Y P 1 B 1$ has been shown to be overexpressed in various malignant tumors (47). Barnett et al. demonstrated that CYPIB1 is expressed in gliomas (48) and the level of expression depends on tumor type and grade (43). Aldehyde oxidases and GSTs along with their isoenzyme glutathione $S$-transferase pi 1 (GSTP1), were also upregulated in this study. Aldehyde oxidases take part in the metabolism of alkylating agents mediating resistance to anticancer drugs (49), while phase II drug-metabolizingenzymes, GSTs, are responsible for catalyzing the formation of glutathione-S-conjugates with electrophiles, inactivating and facilitating excretion of these drug molecules (50). Previous studies stated that GST genes were up-regulated in response to oxidative stress and inexplicably overexpressed in many tumors, causing problems during cancer chemotherapy by directly affecting drug metabolism or by potentially reducing the ability of the drugs to interact with DNA and other cellular molecules (51). GSTP1 is the primary isoenzyme contributing to total GST activity in both normal brain and brain tumors $(42,52)$. Hara et al. also examined expression of GSTP1 in 31 gliomas and six normal brain tissues and showed that gliomas had a strongly positive reaction for GSTP1 immunostaining in both in vitro models and patient glioma samples (53).

Another mechanism mediating multiple drug resistance is the active efflux of anticancer drugs out of cells through multidrug-resistance proteins embedded in the cellular 


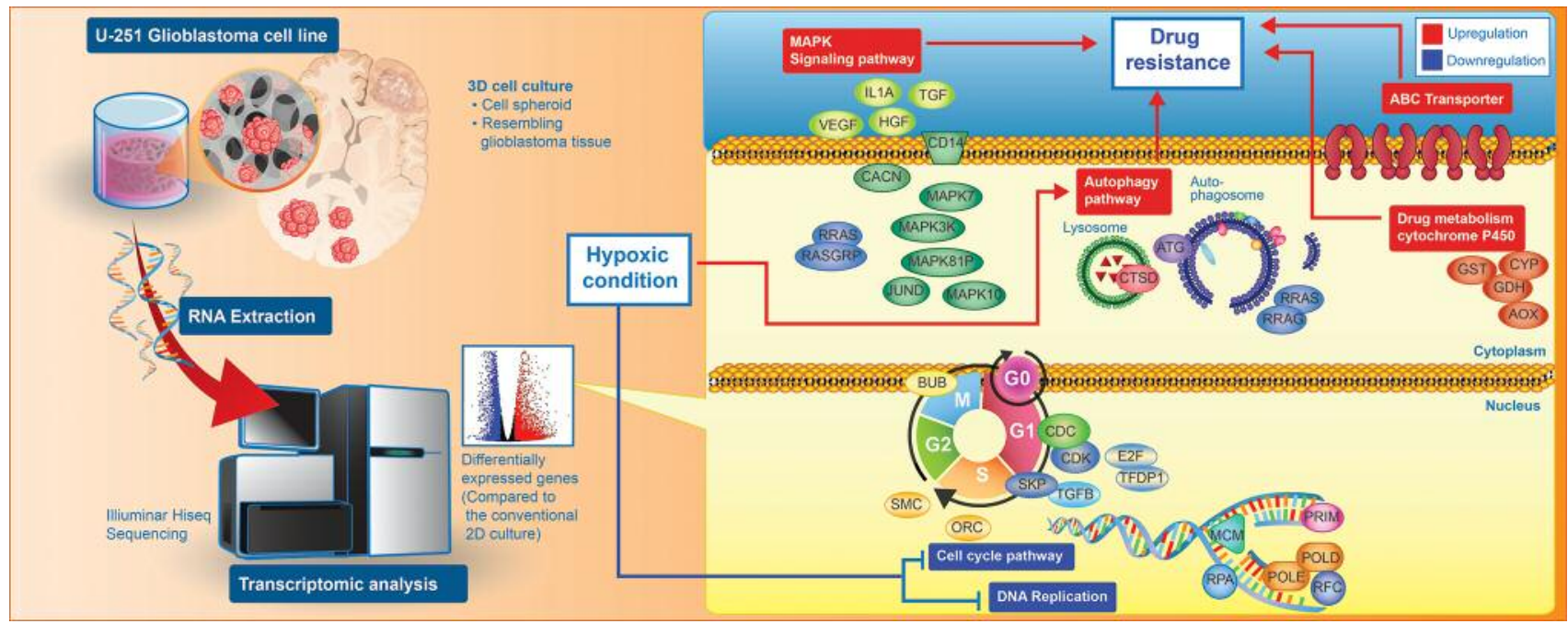

Figure 8. Graphical illustration of the approach to investigation of the mechanisms of anticancer drug resistance by transcriptomic profiling of $3 D$ glioblastoma tumoroids. MAPK: Mitogen-activated protein kinases; IL1A: interleukin 1 alpha; TGF: transforming growth factor; VEGF: vascular endothelial growth factor; HGF: hepatocyte growth factor; CD14: CD14 molecule; CACN: calcium voltage-gated channel subunits; RRAS: RAS related; RASGRP: RAS guanyl releasing protein; JUND: JunD proto-oncogene, AP-1 transcription factor subunit; CTSD: cathepsin D; ATG: autophagy related; RRAG: Ras related GTP binding; ABC: ATP-binding cassette; GST: glutathione S-transferases; CYP: cytochrome P450s; GDH: glucose dehydrogenase; AOX: aldehyde oxidase; G0: Gap 0; G1: Gap 1; G2: Gap 2; S: synthesis phase; M: mitosis phase; BUB: budding uninhibited by benzimidazoles; SMC: structural maintenance of chromosomes proteins; ORC: origin recognition complex; SKP: S-phase kinase associated protein; TGFB: transforming growth factor beta family; CDK: cyclin dependent kinases; CDC: cell division cycle; E2F: E2F transcription factors; TFDP1: transcription factor Dp-1; MCM: minichromosome maintenance complex; RPA: replication protein A; PRIM: DNA primase subunit; POLD: DNA polymerase delta; POLE: DNA polymerase epsilon, catalytic subunit; RFC: replication factor C subunit.

membrane (54). Drugs can be transported across the membrane against electrochemical potentials in ATPdependent manner via $\mathrm{ABC}$ transporters, which were found to be up-regulated in this study (Figure 6F). The family of ABC transporters is involved in diverse physiological processes and responsible for the uptake and efflux of broad type of substances from cancer cells (55). Rama, et al. demonstrated that $A B C A 1, A B C C 4$, and $A B C C 5$ were overexpressed in glioblastoma cells and drug resistance has been correlated with the presence of $\mathrm{ABC}$ transporters (56).

Our work has provided transcriptomic perspective and quantitative measurements of genes differently expressed in glioblastoma cells under 2D and 3D in vitro culture conditions. Based on our findings, future research should investigate data from proteomics and metabolomics in order to understand cell phenotype and identify novel therapeutic targets in glioblastoma (Figure 8). The in vitro 3D glioblastoma culture model has the potential to serve as a powerful platform for tumor study and anticancer drug screening and potentially be applied to further proteomic and metabolomics studies.

\section{Conflicts of Interest}

There are no conflicts of interest.

\section{Authors' Contributions}

NC performed experiments, collected samples, analyzed and interpreted the data, wrote the article, prepared the article for publication and article revision. PK performed experiments, analyzed and interpreted the data. WP performed experiments. NR performed experiments, analyzed and interpreted data. $\mathrm{NH}$ performed experiments. NS performed experiments. PN provided resources, concept, and design of the study, prepared the article for publication, and finally approved the article.

\section{Acknowledgements}

This work was supported by the National Research Council of Thailand (NRCT), Suranaree University of Technology (SUT), One Research One Grant (OROG) Scholarship, and by Office of the Higher Education Commission under NRU Project of Thailand.

\section{References}

1 Behin A, Hoang-Xuan K, Carpentier AF and Delattre J-Y: Primary brain tumours in adults. Lancet 361(9354): 323-331, 2003. PMID: 30060998. DOI: 10.1016/S0140-6736(18)30990-5

2 Johnson DR and O'Neill BP: Glioblastoma survival in the united states before and during the temozolomide era. J Neurooncol 107(2): 359-364, 2012. PMID: 22045118. DOI: 10.1007/s11060011-0749-4 
3 Clark PA, Bhattacharya S, Elmayan A, Darjatmoko SR, Thuro BA, Yan MB, van Ginkel PR, Polans AS and Kuo JS: Resveratrol targeting of akt and p53 in glioblastoma and glioblastoma stem-like cells to suppress growth and infiltration. J Neurosurg 126(5): 448-1460, 2016. PMID: 27419830. DOI:10.3171/2016.1.JNS152077

4 Beier CP, Kumar P, Meyer K, Leukel P, Bruttel V, Aschenbrenner I, Riemenschneider MJ, Fragoulis A, Rümmele P and Lamszus $\mathrm{K}$ : The cancer stem cell subtype determines immune infiltration of glioblastoma. Stem Cells Dev 21(15): 2753-2761, 2012. PMID: 22676416. DOI: 10.1089/scd.2011.0660

5 Kang M-K and Kang S-K: Tumorigenesis of chemotherapeutic drug-resistant cancer stem-like cells in brain glioma. Stem Cells Dev 16(5): 837-848, 2007. PMID: 17999604. DOI: 10.1089/ scd.2007.0006

6 Abbott A: Cell culture: Biology's new dimension. Nature 424(6951): 870-872, 2003. PMID: 12931155. DOI: 10.1038/ $424870 \mathrm{a}$

7 Stavrinou P, Mavrogiorgou M-C, Polyzoidis K, Kreft-Kerekes V, Timmer M, Marselos M and Pappas P: Expression profile of genes related to drug metabolism in human brain tumors. PloS one 10(11): e0143285, 2015. PMID: 26580399. DOI: 10.1371/ journal.pone. 0143285

8 Friedrich J, Seidel C, Ebner R and Kunz-Schughart LA: Spheroid-based drug screen: Considerations and practical approach. Nat Protoc 4(3): 309, 2009. PMID: 19214182. DOI: 10.1038/nprot.2008.226

9 Kievit FM, Florczyk SJ, Leung MC, Veiseh O, Park JO, Disis ML and Zhang M: Chitosan-alginate 3D scaffolds as a mimic of the glioma tumor microenvironment. Biomaterials 31(22): 5903-5910, 2010. PMID: 20417555. DOI: 10.1016/ j.biomaterials.2010.03.062

10 Lv D, Yu SC, Ping YF, Wu H, Zhao X, Zhang H, Cui Y, Chen B, Zhang X, Dai J, Bian XW and Yao XH: A three-dimensional collagen scaffold cell culture system for screening anti-glioma therapeutics. Oncotarget 7(35): 56904-56914, 2016. PMID 27486877. DOI: 10.18632 /oncotarget.10885

11 Chaicharoenaudomrung N, Kunhorm P, Promjantuek W, Heebkaew N, Rujanapun N and Noisa P: Fabrication of 3D calcium-alginate scaffolds for human glioblastoma modeling and anticancer drug response evaluation. J Cell Physiol 234: 2008520097, 2019. PMID: 30945284. DOI: 10.1002/jcp.28608

12 Ma L, Zhang B, Zhou C, Li Y, Li B, Yu M, Luo Y, Gao L, Zhang D and Xue Q: The comparison genomics analysis with glioblastoma multiforme (GBM) cells under 3D and 2D cell culture conditions. Colloids Surf B Biointerfaces 1(172): $665-$ 673, 2018. PMID: 30243220. DOI: 10.1016/j.colsurfb.2018. 09.034

13 Tejero R, Huang Y, Katsyv I, Kluge M, Lin J-Y, Tome-Garcia J, Daviaud N, Wang Y, Zhang B and Tsankova NM: Gene signatures of quiescent glioblastoma cells reveal mesenchymal shift and interactions with niche microenvironment. EBioMedicine 42: 252-269, 2019. PMID: 30952620. DOI: 10.1016/j.ebiom.2019.03.064

14 Jia W, Jiang X, Liu W, Wang L, Zhu B, Zhu H, Liu X, Zhong M, Xie D and Huang W: Effects of three-dimensional collagen scaffolds on the expression profiles and biological functions of glioma cells. Int J Oncol 52(6): 1787-1800, 2018. PMID: 29568859. DOI: $10.3892 /$ ijo.2018.4330

15 Anders S and Huber W: Differential expression analysis for sequence count data. Genome Biol 11(10): R106, 2010. PMID: 22722343. DOI: $10.1101 /$ gr.133744.111

16 Anders S and Huber W: Differential expression of RNA-Seq data at the gene level-the DESeq package. Heidelberg, Germany: European Molecular Biology Laboratory (EMBL), 2012. Available at: http://www.bioconductor.org/packages/devel/bioc/vignettes/ DESeq/inst/doc/DESeq.pdf (last accessed March 1, 2014)

17 Mortazavi A, Williams BA, McCue K, Schaeffer L and Wold B: Mapping and quantifying mammalian transcriptomes by RNASeq. Nat Methods 5(7): 621, 2008. PMID: 18516045. DOI: 10.1038/nmeth.1226

18 Kanehisa M, Araki M, Goto S, Hattori M, Hirakawa M, Itoh M, Katayama T, Kawashima S, Okuda S and Tokimatsu T: KEGG for linking genomes to life and the environment. Nucleic Acids Res 36: D480-D484, 2007. PMID: 18077471. DOI: 10.1093/ nar/gkm882

19 Shaw AT, Yasothan U and Kirkpatrick P: Crizotinib. Nat Rev Drug Discov 10(12): 897-898, 2011. PMID: 22129984. DOI: $10.1038 / \mathrm{nrd} 3600$

20 Ledford H: Translational research: 4 ways to fix the clinical trial. Nature 477(7366): 526-528, 2011. PMID: 21956311. DOI: $10.1038 / 477526 a$

21 Yamada KM and Cukierman E: Modeling tissue morphogenesis and cancer in 3D. Cell 130(4): 601-610, 2007. PMID: 17719539. DOI: $10.1016 /$ j.cell.2007.08.006

22 Tekin H, Simmons S, Cummings B, Gao L, Adiconis X, Hession CC, Ghoshal A, Dionne D, Choudhury SR and Yesilyurt V: Effects of 3D culturing conditions on the transcriptomic profile of stem-cell-derived neurons. Nat Biomed Eng 2(7): 540, 2018. PMID: 30271673. DOI: 10.1038/s41551-018-0219-9

23 Senkowski W, Jarvius M, Rubin J, Lengqvist J, Gustafsson MG, Nygren P, Kultima K, Larsson R and Fryknäs M: Large-scale gene expression profiling platform for identification of contextdependent drug responses in multicellular tumor spheroids. Cell Chem Biol 23(11): 1428-1438, 2016. PMID: 27984028. DOI: 10.1016/j.chembiol.2016.09.013

$24 \mathrm{Kim}$ JB: Three-dimensional tissue culture models in cancer biology. Semin Cancer Biol 15(5): 365-377, 2005. PMID: 15975824. DOI: 10.1016/j.semcancer.2005.05.002

25 Florczyk SJ, Kievit FM, Wang K, Erickson AE, Ellenbogen RG and Zhang M: 3D porous chitosan-alginate scaffolds promote proliferation and enrichment of cancer stem-like cells. J Mater Chem B 4(38): 6326-6334, 2016. PMID: 28133535. DOI: $10.1039 / \mathrm{C} 6 \mathrm{~TB} 01713 \mathrm{D}$

26 Richards R, Jenkinson MD, Haylock BJ and See V: Cell cycle progression in glioblastoma cells is unaffected by pathophysiological levels of hypoxia. PeerJ 3 (4): e1755, 2016. PMID: 26966676. DOI: 10.7717/peerj.1755

27 Cheung TH and Rando TA: Molecular regulation of stem cell quiescence. Nat Rev Mol Cell Biol 14(6): 329, 2013. PMID: 23698583. DOI: $10.1038 / \mathrm{nrm} 3591$

28 Dunn KL, Espino PS, Drobic B, He S and Davie JR: The RASMAPK signal transduction pathway, cancer and chromatin remodeling. Biochem Cell Biol 83(1): 1-14, 2005. PMID: 15746962. DOI: $10.1139 / \mathrm{o} 04-121$

29 Xu P, Zhang G, Hou S and Sha L-g: MAPK8 mediates resistance to temozolomide and apoptosis of glioblastoma cells through MAPK signaling pathway. Biomed Pharmacother 106: 14191427, 2018. PMID: 30119215. DOI: 10.1016/j.biopha. 2018.06 .084 
30 Motta C, D'angeli F, Scalia M, Satriano C, Barbagallo D, Naletova I, Anfuso CD, Lupo G and Spina-Purrello V: PJ-34 inhibits parp1 expression and ERK phosphorylation in glioma-conditioned brain microvascular endothelial cells. Eur J Pharmacol 15(761): 55-64, 2015. PMID: 25934569. DOI: 10.1016/j.ejphar.2015.04.026

31 Zhou Y-Y, Li Y, Jiang W-Q and Zhou L-F: MAPK/JNK signalling: A potential autophagy regulation pathway. Biosci Rep 35(3): e00199, 2015. PMID: 26182361. DOI: 10.1042/ BSR20140141

32 Lin C-J, Lee C-C, Shih Y-L, Lin C-H, Wang S-H, Chen T-H and Shih C-M: Inhibition of mitochondria-and endoplasmic reticulum stress-mediated autophagy augments temozolomideinduced apoptosis in glioma cells. PloS one 7(6): e38706, 2012 PMID: 22745676. DOI: 10.1371/journal.pone.0038706

33 Bingel C, Koeneke E, Ridinger J, Bittmann A, Sill M, Peterziel $\mathrm{H}$, Wrobel JK, Rettig I, Milde T and Fernekorn U: Threedimensional tumor cell growth stimulates autophagic flux and recapitulates chemotherapy resistance. Cell Death Dis $8(8)$ : e3013, 2017. PMID: 28837150. DOI: 10.1038/cddis.2017.398

34 Altman BJ, Stine ZE and Dang CV: From Krebs to clinic: Glutamine metabolism to cancer therapy. Nat Rev Cancer 16(10): 619, 2016. PMID: 27492215. DOI: $10.1038 / \mathrm{nrc} .2016 .71$

35 Liberti MV and Locasale JW: The Warburg Effect: How Does it Benefit Cancer Cells? Trends Biochem Sci 41(3): 211-218, 2016. PMID: 26778478. DOI: 10.1016/j.tibs.2015.12.001

36 La Schiazza R, Lamari F, Foglietti MJ, Hainque B, Bernard M and Beaudeux JL: Cellular energetic metabolism of cerebral tissue: Metabolic characteristics of glial tumours. Ann Biol Clin (Paris) 66(2): 131-141, 2008. PMID: 18390423. DOI: 10.1684/ abc. 2008.0205

37 Katheder NS, Khezri R, O'Farrell F, Schultz SW, Jain A, Rahman MM, Schink KO, Theodossiou TA, Johansen T and Juhász G: Microenvironmental autophagy promotes tumour growth. Nature 541(7637): 417-420, 2017. PMID: 28077876 DOI: $10.1038 /$ nature20815

38 Levy JMM, Towers CG and Thorburn A: Targeting autophagy in cancer. Nat Rev Cancer 17(9): 528, 2017. PMID: 28751651. DOI: $10.1038 /$ nrc.2017.53

39 Wang L, Shang Z, Zhou Y, Hu X, Chen Y, Fan Y, Wei X, Wu L, Liang $\mathrm{Q}$ and Zhang J: Autophagy mediates glucose starvationinduced glioblastoma cell quiescence and chemoresistance through coordinating cell metabolism, cell cycle, and survival. Cell Death Dis 9(2): 213, 2018. PMID: 29434213. DOI: 10.1038/s41419-017-0242-x

40 Esteller M, Garcia-Foncillas J, Andion E, Goodman SN, Hidalgo OF, Vanaclocha V, Baylin SB and Herman JG: Inactivation of the DNA-repair gene MGMT and the clinical response of gliomas to alkylating agents. N Engl J Med 343(19): 1350-1354, 2000. PMID: 11070098. DOI: 10.1056/NEJM200011093431901

41 Backos DS, Franklin CC and Reigan P: The role of glutathione in brain tumor drug resistance. Biochem Pharmacol 83(8): 10051012, 2012. PMID: 22138445. DOI: 10.1016/j.bcp.2011.11.016

42 Lo H-W and Ali-Osman F: Genetic polymorphism and function of glutathione s-transferases in tumor drug resistance. Curr Opin Pharmacol 7(4): 367-374, 2007. PMID: 17681492. DOI: 10.1016/j.coph.2007.06.009

43 Agundez JA: Cytochrome P450 gene polymorphism and cancer. Curr Drug Metab 5(3): 211-224, 2004. PMID: 15180491.

44 Zanger UM, Turpeinen M, Klein K and Schwab M: Functional pharmacogenetics/genomics of human cytochromes $\mathrm{P} 450$ involved in drug biotransformation. Anal Bioanal Chem 392(6): 1093-1108, 2008. PMID: 18695978. DOI: 10.1007/s00216-008-2291-6

45 Murray GI, Taylor MC, McFadyen MC, McKay JA, Greenlee WF, Burke MD and Melvin WT: Tumor-specific expression of cytochrome P450 CYP1B1. Cancer Res 57(14): 3026-3031, 1997. PMID: 9230218.

46 Milne E, Greenop KR, Scott RJ, Ashton LJ, Cohn RJ, de Klerk $\mathrm{NH}$ and Armstrong BK: Parental smoking and risk of childhood brain tumors. Int $\mathrm{J}$ Cancer 133(1): 253-259, 2013. PMID: 23280760. DOI: $10.1002 / \mathrm{ijc} .28004$

47 McFadyen MC and Murray GI: Cytochrome P450 1B1: A novel anticancer therapeutic target. Future Oncol 1(2): 259-63, 2005. PMID: 16555997. DOI: 10.1517/14796694.1.2.259

48 Barnett JA, Urbauer DL, Murray GI, Fuller GN and Heimberger AB: Cytochrome P450 1B1 expression in glial cell tumors: An immunotherapeutic target. Clin Cancer Res 13(12): 3559-3567, 2007. PMID: 17575219. DOI: 10.1158/1078-0432.CCR-06-2430

49 Schäfer A, Teufel J, Ringel F, Bettstetter M, Hoepner I, Rasper M, Gempt J, Koeritzer J, Schmidt-Graf F and Meyer B: Aldehyde dehydrogenase 1A1-a new mediator of resistance to temozolomide in glioblastoma. Neuro Oncol 14(12): 1452-1464, 2012. PMID: 23132408. DOI: 10.1093/neuonc/nos270

50 Hayes JD, Flanagan JU and Jowsey IR: Glutathione transferases. Annu Rev Pharmacol Toxicol 45: 51-88, 2005. PMID: 15822171. DOI: 10.1146/annurev.pharmtox.45.120403.095857

51 Sherratt PJ and Hayes JD: Glutathione S-transferases. In enzyme systems that metabolise drugs and other xenobiotics. Ioannides, C (ed.). New York, John Wiley and Son Ltd., pp 319-352, 2002.

52 Strange RC, Fryer AA, Matharoo B, Zhao L, Broome J, Campbell DA, Jones P, Pastor IC and Singh RVP: The human glutathione stransferases: Comparison of isoenzyme expression in normal and astrocytoma brain. Biochim Biophys Acta 1139(3): 222-228, 1992. PMID: 1627661. DOI: 10.1016/0925-4439(92)90138-d

53 Hara A, Yamada H, Sakai N, Hirayama H, Tanaka T and Mori $\mathrm{H}$ : Immunohistochemical demonstration of the placental form of glutathione s-transferase, a detoxifying enzyme in human gliomas. Cancer 66(12): 2563-2568, 1990. PMID: 2174303. DOI: $10.1002 / 1097-0142(19901215) 66: 12<2563::$ aid-cncr 2820 661219>3.0.co;2-a

54 Dréan A, Rosenberg S, Lejeune F-X, Goli L, Nadaradjane AA, Guehennec J, Schmitt C, Verreault M, Bielle F and Mokhtari K: ATP binding cassette (ABC) transporters: Expression and clinical value in glioblastoma. J Neurooncol 138(3): 479-486, 2018. PMID: 29520610. DOI: 10.1007/s11060-018-2819-3

55 Alexiou GA, Goussia A, Voulgaris S, Fotopoulos AD, Fotakopoulos G, Ntoulia A, Zikou A, Tsekeris P, Argyropoulou MI and Kyritsis AP: Prognostic significance of MRP5 immunohistochemical expression in glioblastoma. Cancer Chemother Pharmacol 69(5): 1387-1391, 2012. PMID: 22278731. DOI: $10.1007 / \mathrm{s} 00280-012-1832-\mathrm{z}$

56 Rama AR, Alvarez PJ, Madeddu R and Aranega A: ABC transporters as differentiation markers in glioblastoma cells. Mol Biol Rep 41(8): 4847-4851, 2014. PMID: 25028266. DOI: $10.1007 / \mathrm{s} 11033-014-3423-\mathrm{z}$

Received September 12, 2019

Revised October 7, 2019

Accepted October 11, 2019 